\title{
Virus - On the Edge of Art and Science, Human Beings, and Nature
}

\author{
Tony Yu Zhou \\ Inspirees Institute, China
}

\begin{abstract}
In this article, the author shares his eastern and western perspectives on biomedicine, science and arts as well as his personal experiences during the coronavirus epidemics in China. Virus is described symbolically as a messenger on the edge of art and science, human beings and nature leading to a discussion over the sustainable development of human beings in harmony with nature.
\end{abstract}

Keywords: Coronavirus epidemic, Covid-19, Sustainable development, Entropy, Art, Traditional Chinese medicine

\section{摘要}

本文作者分享了其在中国新冠肺炎疫情期间从生物医学，科学及艺术，东西方视角的思 考和个人感受。病毒被象征性地描述为处于艺术和科学，人类和自然边缘上的信使，从 而引发出关于人类与自然和谐可持续发展的讨论。

关键词 : 冠状病毒疫情，肺炎，可持续发展，熵，艺术，中医

With the outbreak of the coronavirus epidemic in China and its spread worldwide, the public and academics have been discussing the attack of this "new type" of virus on human species and how we can react at biological, social, and economic levels in order to go through this crisis, which started in the late 2019. Yet, examining this issue from different and macro perspectives, we can consider the virus to be acting as the messenger among art and science, human beings, and nature.

So much has been clarified about coronaviruses and other viruses in biology. Viruses are tiny infectious agents that replicate only inside the living cells of an organism, and they have been described as the "miracle biomolecules at the edge of life" (i.e., between life form and non-life form) (Koonin \& Starokadomskyy, 2016). Viruses can infect all types of life forms, from animals and plants to microorganisms. They are considered as non-organisms since they cannot survive outside the host systems they infect. However, such interpretation of viruses based on its dependence on hosts is rather subjective and biased. As the matter of fact, nearly all living forms or organisms are dependent on their living environment and other surrounding systems and processes to provide raw materials or energy (photosynthesis etc.), without which they cannot survive independently. Hence, although human beings are considered the organism, we can also be classified as "parasites/viruses" within some other systems. 
According to thermodynamic theory and research work from Nobel-laureate physicist Erwin Schrödinger and Austrian physicist Ludwig Boltzmann, the general struggle for existence of animate beings is not a struggle for raw materials - these, for organisms, are air, water, and soil, all abundantly available — nor for energy that exists in plenty in anybody in the form of heat, but is a struggle for [negative] entropy (Boltzmann, 1974). Entropy is the quantitative measure of the degree of disorder in any physical system. This means that any life form, whether viruses or human beings, regardless its complexity, needs to create lots of chaos (disorders) in the environment to gain negative entropy in order to build and stabilize itself. Any changes in biodiversity that lead to lower entropy production would be considered detrimental to system stability (Vallino, 2010). Unfortunately, this means human beings or society, on its way to evolve into a highly structured and complex entity, needs to disrupt the surrounding nature and other living system/species including viruses. Thus, it makes sense to consider the coronavirus epidemic in China as a good example of such interaction among different systems: human species release lots of disorders (entropy) to the environment, the virus feels the pressure and reacts by creating chaos to human beings with such a disease in order to stabilize themselves as a system and survive. Ideas about the relationship between entropy and living organisms have inspired hypotheses in many contexts, including psychology, sociology, information theory, the origin of life, and the possibility of extraterrestrial life.

Back to viruses, this simplest form of organisms is very creative (i.e., highly robust to mutate its gene very quick to counteract the medicines produced by human beings). By comparison, the highly evolved and structured human species is much less flexible to adapting to the gene mutation of the virus and thus became vulnerable to the attack of the coronavirus in this case. If we recall the HIV cocktail therapy (Gulick et al., 1997) invented by the Taiwanese-American scientist David Ho, who was inspired by traditional Chinese medicine (TCM) and the yin-yang philosophy, it appears that the ancient Chinese wisdom of creating entropy/chaos in herb soup was applied in the said HIV cocktail therapy. Such approach, like the recent treatment on Covid-19 virus with TCM (Yang et al., 2020), responds to the quick mutations of the malignant virus, whereas Western medicine, when used as a single active chemical component, albeit analytically clear and "correct," sometimes has limitation in fighting viral infections and mutations effectively. Apparently, highly structured entities like human beings have pitfalls, and for the sake of survival as a species or system, it is desirable to have some corresponding entities that are creative and less structured such as art in order to achieve balance and robustness.

I remember the first time I visited the Rockefeller Center in New York. I stood in front of the fresco art (Figures 1 and 2), and I felt overwhelmed and was taken back. The attempt and ambition of human beings to conquer the world and control the nature conveyed by the paintings impressed and intimidated me at the same time. This was intensified by the scale of the artworks, the strong contrast of colors, and the predominant presence of human beings in the paintings, which I hardly saw in the Chinese counterpart. From a biologist's and human being's point of view, I understood our desire to be in the center of the nature, but being someone from a traditional Chinese culture background with reverence to nature, I felt it was such a bold statement to challenge Mother Nature. This coronavirus epidemic strongly reminded me, a biomedical scientist, an arts therapist, 


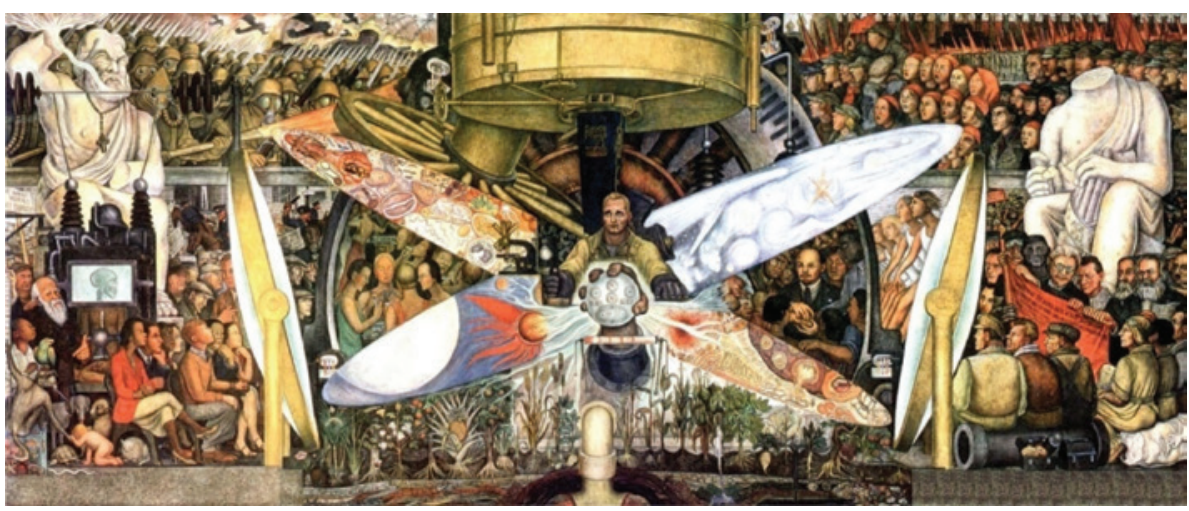

Figure 1. Man at the Crossroads (1934), by Diego Rivera, in the Rockefeller Center, New York. By Gumr51 - own work, CC BY-SA 3.0 (https://commons.wikimedia.org/w/index. php?curid=16276135).

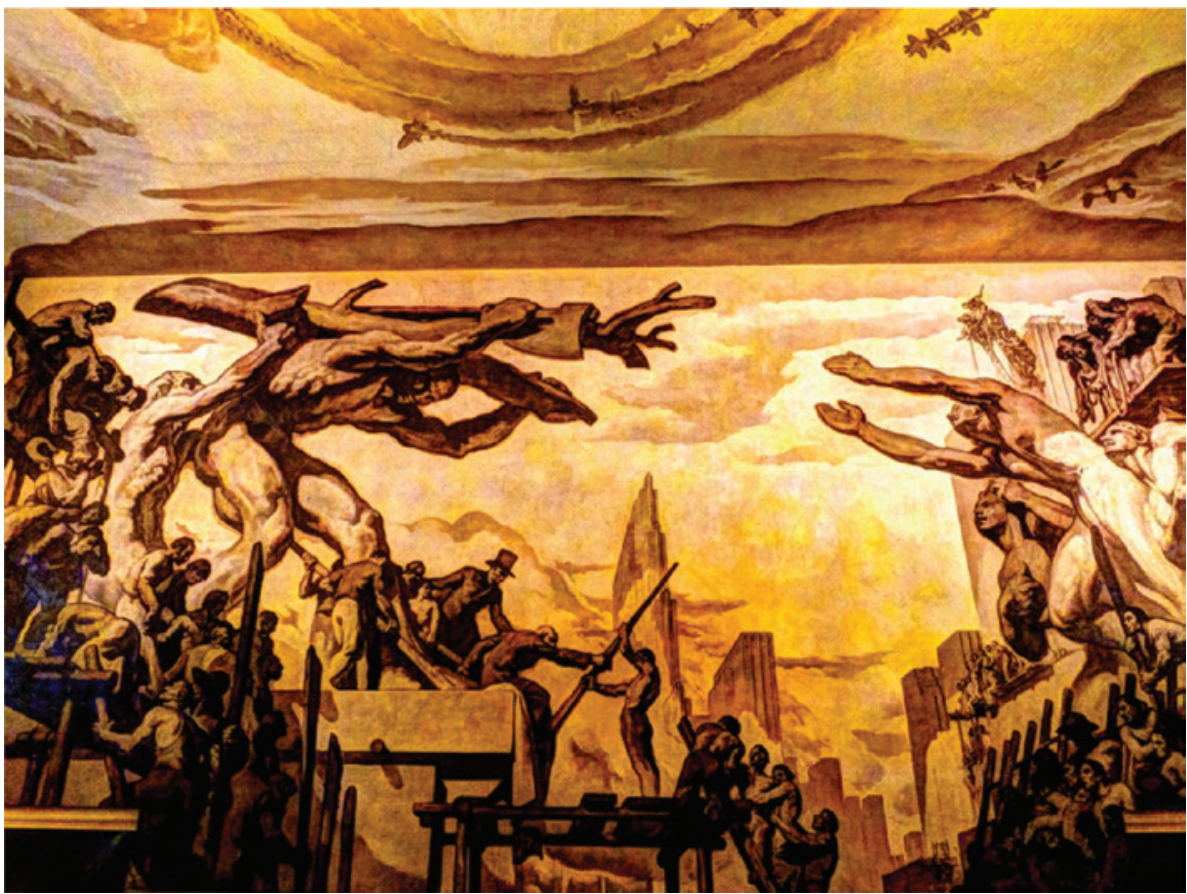

Figure 2. American Progress (1937, part), by Josep Maria Sert in the Rockefeller Center, New York.

and a human being, of how little we know about the universe and how vulnerable we actually can be in the face of such a small and simple biomolecule and living form, reinforcing my respect for nature and understanding of Way (Tao). Nature seems to send coronavirus as a messenger, informing us how we need to think more ecologically and 
to be less egoistic as an individual and species. Although I see the value of the fighting (yang) quality, such as being stronger, bigger, and faster, as driven by the modern civilization, it is sensible to realize that the opposite yin quality, being gentle, smaller, slower, etc., can be also powerful. Many times in my life, I was moved by art, and I remember it was the gentle and elegant music and dance and essentially the feeling of deep connection to nature and other human beings that touched my nerves and brought tears to my eyes. That was the moment my mind, heart, and spirits aligned, and I felt electrified and enlightened. That was the moment I felt I was a true human being.

Richard Oliver (1999), in his book The Coming Biotech Age: The Business of Bio-Materials, demonstrated the evolution curve of human civilizations in the past thousands of years through the Agricultural Revolution, Industrial Age, Information Age, and Bio-material Age. The accelerating growth curve appears to be very similar to those of bacteria and virus. This again shows that, at certain dimensions, we, as the living systems, are all connected and exist and develop in a similar pattern. Human beings, as a system, need to learn to achieve the delicate balance of producing entropy (disorders) to stabilize itself and not destroy other surrounding systems. According to Vallino (2010), bio-systems that produce more entropy over longer time periods is favorable in the Darwinian context of natural selection. He speculates that systems will evolve toward entropy production that is maximized over infinite time and space. Probably, that is the pathway that human species should choose in order to exist longer.

A significant phenomenon we observe is the huge separation this epidemic has created among countries and human beings. Families lost their members who died from the disease, leading to sorrows and trauma. Millions of people who were placed in quarantine for weeks did not have any physical social contact (Figure 3). An atmosphere of fear and suspicion has penetrated our daily life in China and is spreading to other places around the world. I, an expatriate Chinese living in Europe, could feel the heaviness and darkness in the air, and my energy became bound It is not only the biological virus but also the emotionally infecting "virus" based on separation and fear that is undermining humanity and well-being. In fact, human society is experiencing many different separations, leading to increased loneliness, which has become an epidemic nowadays (Anderson, 2010). Although science and technology have progressed dramatically in the past centuries, they still have limitations in tackling the challenges we are facing. Science alone cannot help us reach and effectively understand our emotional and spiritual world, which are essential to human beings going through the disasters. Both science and art are needed hand-inhand to empower human beings to restore themselves from the epidemic catastrophe and help us build social connections and feel more engaged with others (Tymoszuk, Perkins, Fancourt, \& Williamon, 2019; Menzer, 2015; Mathew, Sundar, Subramaniam, \& Parmar, 2017; Bronwyn, Launay, \& Dunbar, 2014). Here, we talk about resilience, the proactive attitude to recover, especially on the psychological level, instead of being passively treated by medicine. This proactive attitude includes the creative use of $c h ' i$, the vital force in human beings. Such creative use and process not only encourages harmonious, comforting, bound, and structured expressions but also gives space for the wild and dark side. We are strongly experiencing the wild and negative energy of this coronavirus epidemic (e.g., isolation, loneliness, anger, sadness, depression, hopelessness, boredom, 

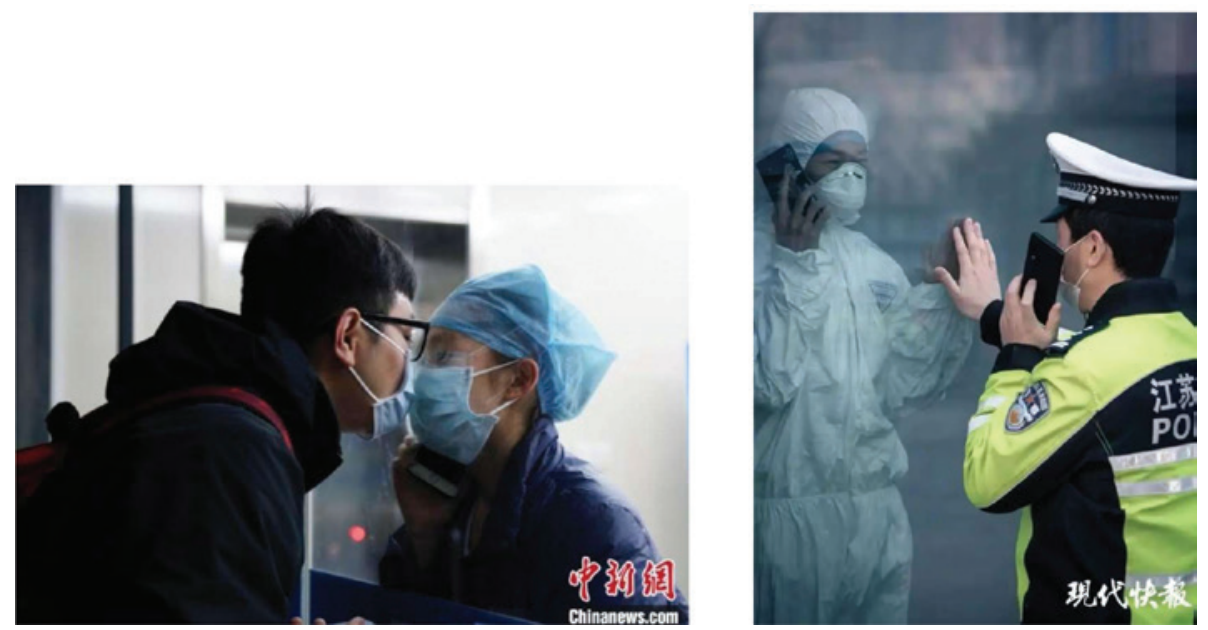

Figure 3. Chinese young couples expressing the love for each other while fighting against the coronavirus epidemic, courtesy of Chinanews and Modern Newspaper. A photo collection from

Wuhan, the epicenter, can be found on http://caet.inspirees.com/collection-of-photos-fromwuhan-china-coronavirus-epicenter/.

resistance). If we can embrace these dark energies and use them as an opportunity to follow the Tao and transform them through artistic expression, we are likely to generate the satisfaction, calm, and well-being that we may ultimately seek, as discussed and emphasized by Levine (2015) and McNiff (2016) in their work with ch'i and Tao. The Chinese word for crisis (危机) consists of both threat and opportunity, which reflects the philosophy of the yin-yang transformative energy in the life process.

After the lockdown of many cities and communities in China, many of us had to stay home, which eventually provided the opportunity to spend much more with our family members and reflect inwardly, which we usually were not able to do. Lots of arts therapy training courses had to be cancelled. Our students and colleagues experienced a huge vacuum in time and space during the isolation. As a counteraction, we organized some online learning programs to support our professional communities. It was such an amazing experience to see so many faces and moving bodies in a big group on the screen at the same time albeit virtual reality. We were so excited to get connected to other human beings in other parts of the world. During the sharing, the two words most mentioned were acceptance and expansion (i.e., to accept different way of life living with the virus and expand our perspectives in different dimensions after our kinesphere was squeezed). Ironically, the coronavirus, which separated and shrunk us, united and expanded us at the same time. Some call coronaviruses as the enemy we are fighting. Will it be more sensible to consider viruses as part of the ecology system and consider the process as transformation instead of fighting? It might be helpful to, instead of trying to kill the virus, think of how we can enhance our own immunity and build a more harmonious way of coexisting with other eco-systems.

This coronavirus epidemic is a dialogue between nature and human beings, who, together with our civilization, are standing on the edge of the next stage of evolution. 


\section{About the Author}

Tony Y. Zhou, $\mathrm{PhD}$, is the founder and director of Inspirees Institute, China/Netherlands. $\mathrm{He}$ is also the founder and executive editor of CAET. He was trained as the biomedical scientist and later received training in dance/movement therapy and is the first certified Laban movement analyst in mainland China. He cofounded the International Association of Creative Arts Somatic Education in 2019. ORCID: 0000-0001-8099-6458.

\section{References}

Anderson, G. O. (2010). Loneliness among older adults: A national survey of adults 45+. Washington, DC: AARP Research. doi: 10.26419/res.00064.001

Arnheim, R. (1971). Entropy and art-An essay on disorder and order. Berkeley, CA: University of California Press.

Boltzmann, L. (1974). The second law of thermodynamics (theoretical physics and philosophical problems). New York: Springer-Verlag.

Bronwyn, T., Launay, J., \& R. I. M. Dunbar (2014). Music and social bonding: "Self-other" merging and neurohormonal mechanisms. Frontiers in Psychology, 5, 1096. doi: 10.3389/fpsyg.2014.01096

Gulick, R. M., Mellors, J. W., Havlir, D., Eron, J. J., Gonzalez, C., McMahon, D., Richman, D. D., Valentine, F. T., Jonas, L., Meibohm, A., Emini, E. A., \& Chodakewitz, J. A. (1997). Treatment with indinavir, zidovudine, and lamivudine in adults with human immunodeficiency virus infection and prior antiretroviral therapy. New England Journal Medicine, 337(11), 734-739.

Koonin, E. V., Starokadomskyy, P. (2016). Are viruses alive? The replicator paradigm sheds decisive light on an old but misguided question. Studies in History and Philosophy of Biological and Biomedical Sciences, 59, 125-34. doi: 10.1016/j.shpsc.2016.02.016

Kopytin, A. B., Zhou, T. Y. (2019). From ikebana to botanical arranging: Artistic, therapeutic, and spiritual alignment with nature. Creative Arts in Education and Therapy (CAET), 5(2), 96-108. doi: 10.15212/ CAET/2019/5/35

Levine, S. K. (2015). The Tao of poiesis: Expressive arts therapy and Taoist philosophy. Creative Arts in Education and Therapy, 1(1), 15-25. doi: 10.15534/CAET/2015/1/4

Mathew, D., Sundar, S., Subramaniam, E., \& Parmar, P. N. (2017). Music therapy as group singing improves Geriatric Depression Scale score and loneliness in institutionalized geriatric adults with mild depression: A randomized controlled study. International Journal of Educational and Psychological Researches, 3(1), 6-10.

McNiff, S. (2016). Ch'i and artistic expression: An East Asian worldview that fits the creative process everywhere. Creative Arts in Education and Therapy, 2(2), 12-20. doi: 10.15534/CAET/2016/2/6

Menzer, M. (2015). The arts in early childhood: Social and emotional benefits of arts participation-A literature review and gap-analysis (2000-2015). Washington DC: NEA Office of Research and Analysis. Retrieved March 13, 2020, from https://www.arts.gov/sites/default/files/arts-in-early-childhooddec2015-rev.pdf

Oliver, R. (1999). The coming Biotech Age: The business of bio-materials. New York: McGraw-Hill.

Sigaki, H. Y. D., Perc, M., \& Ribeiro, H. V. (2018). History of art paintings through the lens of entropy and complexity. Proceedings National Academy of Sciences of the USA, 115(37), 8585-8594. doi: 10.1073/ pnas. 1800083115

Tymoszuk, U., Perkins, R., Fancourt, D., \& Williamon, A. (2019). Cross-sectional and longitudinal associations between receptive arts. Social Psychiatry and Psychiatric Epidemiology, 1-10. doi: 10.1007/ s00127-019-01764-0

Vallino, J. J. (2010). Ecosystem biogeochemistry considered as a distributed metabolic network ordered by maximum entropy production. Philosophical Transactions of the Royal Society, B, 365(1545), 14171427. doi: 10.1098/rstb.2009.0272

Yang, Y., Islam S., Wang, J., Li, Y., \& Chen, X. (2020). Traditional chinese medicine in the treatment of patients infected with 2019-new coronavirus (sars-cov-2): A review and perspective. International Journal of Biological Sciences, 16(10), 1708-1717. doi: 10.7150/ijbs.45538 